\title{
A THEORETICAL STUDY OF ADSORPTION EQUILIBRIA IN SILICON CVD
}

\author{
J.G.E. GARDENIERS and L.J. GILING \\ Department of Experimental Solid State Physics III, Research Institute for Materials, University of Nijmegen, Toernooiveld, \\ 6525 ED Nijmegen, The Netherlands
}

and

\author{
F. DE JONG and J.P. VAN DER EERDEN \\ Department of Solid State Chemistry, Research Institute for Materials, University of Nijmegen, Toernooiveld, 6525 ED Nijmegen, \\ The Netherlands
}

Received 2 May 1990

\begin{abstract}
As part of a theoretical study of adsorption processes in the chemical vapour deposition of silicon, thermochemical data are derived for the adsorption of $\mathrm{Si}-\mathrm{H}$ species on the $\mathrm{Si}(111)$ and the dimer-reconstructed $\mathrm{Si}(001)-(2 \times 1)$ surfaces. Essential contributions to the heats of adsorption appear to be electron pairing and two- and three-body interactions. It is shown that when the bond energies are defined in this way, also a consistent description of the bonds in silicon hydrides is provided. This demonstrates that with reasonable confidence the method can be applied to the adsorption process itself. Data are derived for species which may form one, two or even four bonds with the surface. It is assumed that on the (111) surface adsorbates bind on the "dangling bonds" which are present on this surface in a broken bond model. It is demonstrated that on the dimer reconstructed $\operatorname{Si}(001)-(2 \times 1)$ surface, adsorbates will either bind on the surface atoms with one or two bonds, without the breaking of the dimer bonds, or, if the species have the possibility to form two or four bonds with the surface atoms, may become inserted into the dimer bonds. With the aid of the derived thermochemical data for adsorption and the Langmuir isotherm or modifications thereof, the coverage of the Si(111) and the dimer reconstructed $\mathrm{Si}(001)-(2 \times 1)$ surfaces with species from the $\mathrm{Si}-\mathrm{H}$ system is calculated. It is found that the equilibrium surface coverages of the $\mathrm{Si}(111)$ and the $\mathrm{Si}(001)-(2 \times 1)$ surfaces are very similar: the hydrogen coverage is high at all temperatures, while at low supersaturation the coverage with growth species is very low on both surfaces.
\end{abstract}

\section{Introduction}

Inspired by several papers of Chernov and coworkers on the calculation of the coverage of $\mathrm{Si}$ and GaAs surface during growth from the respective chloride-CVD systems [1-4], in a previous paper one of the authors reported a theoretical study of adsorption processes on $\mathrm{Si}(111)$ during chemical vapour deposition (CVD) of silicon from silane [5]. Among other things it was shown that at $1 \mathrm{~atm} \mathrm{H}_{2}$ pressure monatomic hydrogen will be the most important adsorbate, while $\mathrm{SiH}_{2}$ will be the most abundant growth species on the surface, its coverage being dependent on the supersaturation.
In this paper the work of ref. [5] will be extended. Different thermochemical data for the gas phase species $\mathrm{SiH}_{2}$ and $\mathrm{SiH}_{3}$ will be used, and the importance of several species that were previously not considered, will be investigated. In contrast to ref. [5], where for all silicon-containing adsorbates the same bond strength with the surface was taken, we shall try to differentiate these bond strengths in the present work by the inclusion of three-body interactions and electron pairing energies. Furthermore, in addition to the adsorption processes considered in ref. [5], adsorbates with more than one chemical bond to the crystal surface will be considered. The discussion will be extended to the dimer reconstructed $\mathrm{Si}(001)$ surface. 


\section{Equilibrium gas phase composition in the $\mathbf{S i}-\mathbf{H}$ system}

For the calculation of the coverage of the silicon surface, knowledge of the composition of the gas phase, which is in contact with the surface, is essential. The equilibrium partial pressures of the relevant gas phase species can be calculated when all the required thermochemical data are known. The calculations proceed along the same lines as described in ref. [5].

On the basis of several recent studies on the thermodynamic properties of gaseous silicon hydrides, we decided to use formation enthalpies of the gas phase species $\mathrm{SiH}_{2}$ and $\mathrm{SiH}_{3}$ different from the ones used in ref. [5]. The usually accepted value of the formation enthalpy of $\mathrm{SiH}_{2}$ of $243 \mathrm{~kJ}$ $\mathrm{mol}^{-1}$ has been criticized by Ho et al. [6]. These authors suggest a value of $285 \mathrm{~kJ} \mathrm{~mol}^{-1}$, while additional evidence exists (see ref. [7] and references therein) that the enthalpy should indeed be higher than the value of $243 \mathrm{~kJ} \mathrm{~mol}^{-1}$, which was used in ref. [5]. However, as no clear argument exists to give preference to any of these values, we decided to use an intermediate value of $270 \mathrm{~kJ}$ $\mathrm{mol}^{-1}$. Furthermore, in order to have a more consistent set of thermochemical data, a value of $200 \mathrm{~kJ} \mathrm{~mol}^{-1}$ will be assumed for $\Delta H_{\mathrm{f}, 298}^{\circ}$ of $\mathrm{SiH}_{3}$, as suggested in ref. [7], instead of the value of $209.4 \mathrm{~kJ} \mathrm{~mol}^{-1}$ used in ref. [5].

For the sake of completeness, we included several gas phase species which were not considered in ref. [5], viz. $\mathrm{Si}_{2} \mathrm{H}_{5}, \mathrm{H}_{3} \mathrm{SiSiH}, \mathrm{H}_{2} \mathrm{SiSiH}_{2}$ and $\mathrm{Si}_{3} \mathrm{H}_{8}$, with thermochemical data from refs. [7,8]. Although the species $\mathrm{Si}_{2} \mathrm{H}_{3}$ and $\mathrm{Si}_{2} \mathrm{H}_{2}$ might also be important in the gas phase (see ref. [9]), these will not be included in our calculations because of a lack of structural information. The thermochemical data of all gas phase species other than the ones mentioned above are rather well accepted and are the same as used in ref. [5].

With these changes and additions the equilibrium gas phase composition as a function of the temperature $T$ was calculated for the two extreme situations mentioned in ref. [5], viz. the so-called "homogeneous" (for an input mixture of $1 \% \mathrm{SiH}_{4}$ in $\mathrm{H}_{2}$ at $1 \mathrm{~atm}$ ) and "heterogeneous" equilibrium situations, which may be considered to correspond

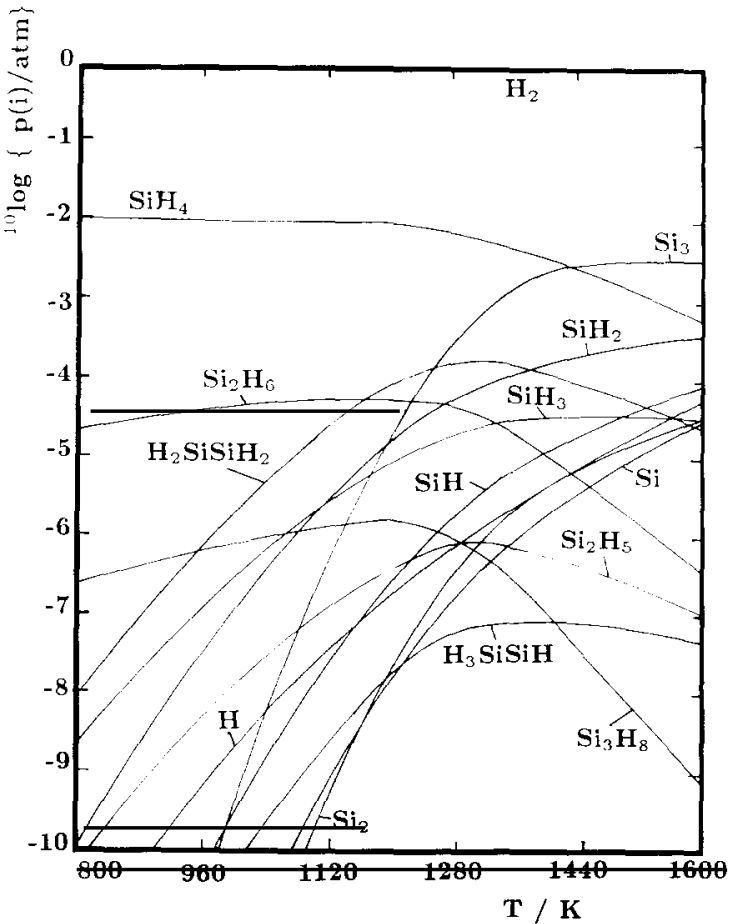

Fig. 1. Equilibrium gas phase composition in the $\mathrm{Si}-\mathrm{H}$ system at $1 \mathrm{~atm}$ as a function of temperature, in the homogeneous equilibrium assumption for an input mixture of $1 \% \mathrm{SiH}_{4}$ in $\mathrm{H}_{2}$.

with high and zero supersaturation, respectively. The results are shown in figs. 1 and 2 . The reader should take care when comparing these figures: the vertical scales in the two figures are not the same.

The most relevant change in the gas phase equilibrium composition with respect to ref. [5] is the following: because of the above-mentioned changes in the formation enthalpies of $\mathrm{SiH}_{2}$ and $\mathrm{SiH}_{3}$, the partial pressure of $\mathrm{SiH}_{2}$ is approximately two decades lower at the lower temperatures and one decade at the higher temperatures for both the homogeneous and the heterogeneous case; in contrast to the findings in ref. [5], where at all temperatures $\mathrm{SiH}_{2}$ was found to be the most important unsaturated silicon compound in the gas phase in the heterogeneous equilibrium, now below approximately $1100 \mathrm{~K} \mathrm{SiH}_{3}$ is more important. Above $1100 \mathrm{~K} \mathrm{SiH}_{2}$, is still the most important growth species in the gas phase. In the 


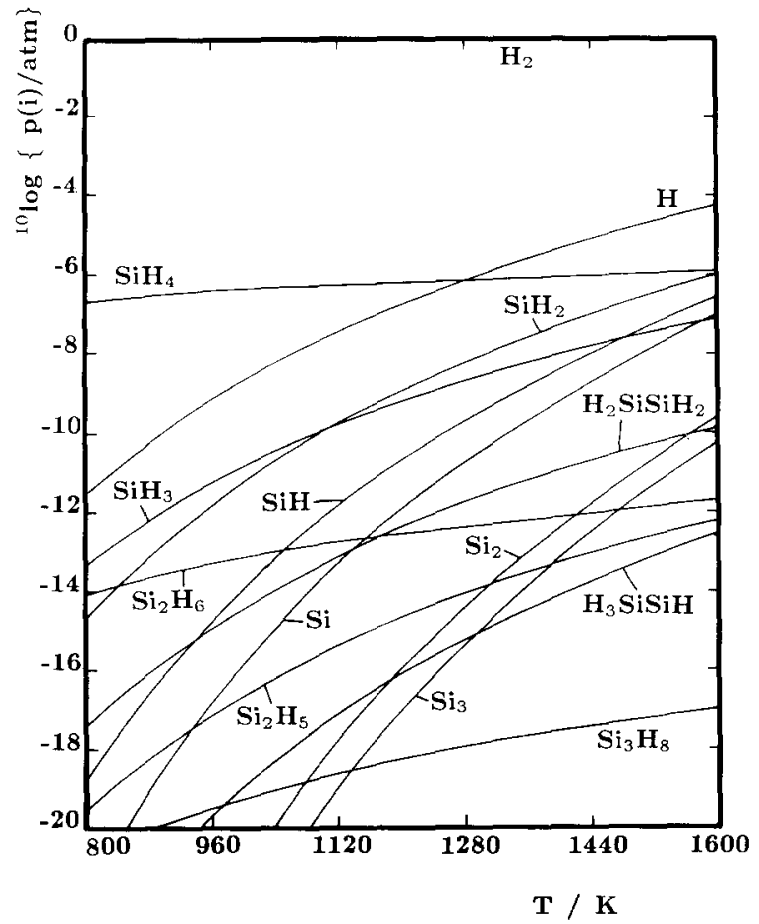

Fig. 2. Equilibrium gas phase composition in the $\mathrm{Si}-\mathrm{H}$ system at $1 \mathrm{~atm}$ as a function of temperature, in the heterogeneous equilibrium assumption.

homogeneous case $\mathrm{SiH}_{3}$ is important at low temperatures, whereas $\mathrm{Si}_{3}$ is the dominating species at the higher temperatures.

\section{Adsorption model and estimation of thermody- namic data for adsorption}

\subsection{General considerations concerning the adsorp- tion model}

In accordance with the commonly accepted notion that the interaction of gas phase species and semiconductor surfaces results in the formation of stable chemical bonds between the species and the surface atoms (see ref. [10] and references therein), in this paper the so-called "dangling bonds" on the surfaces will be considered as the locations on the surface where adsorbates may bind. Bonds of adsorbates with the surface will be considered equivalent to bonds in silicon compounds. This assumption allows an estimation to be made of relevant adsorption parameters like adsorption heats and entropies from the extensive literature on silicon chemistry. The estimations for adsorption on (111) and dimer reconstructed $(001)-(2 \times 1)$ will be worked out in separate sections. It will be assumed that only chemically unsaturated species will be able to adsorb on the silicon surface.

The adsorption processes to be discussed here will be considered as simple chemical equilibria of the general form:

$\mathrm{X}_{\text {gas }}+$ site $\rightleftharpoons \mathrm{X}_{\text {adsorbed }}$.

With this equilibrium reaction, an adsorption constant is associated, $K_{\text {ad,X }}$, which can be calculated with the aid of the equation:

$R T \ln K_{\mathrm{ad}, \mathrm{X}}=-\Delta H_{\mathrm{ad} . \mathrm{X}}^{\circ}+T \Delta S_{\mathrm{ad}, \mathrm{X}}^{\circ}$,

where $\Delta H_{\mathrm{ad}, \mathrm{X}}^{\circ}$ and $\Delta \mathrm{S}_{\mathrm{ad}, \mathrm{X}}^{\circ}$ are the standard enthalpy and entropy changes during the adsorption of the species $\mathrm{X}$, respectively, at temperature $T$. As described in ref. [5], these parameters can be derived from molecular properties with the use of statisticalthermodynamical methods. We shall discuss this more detailed below.

3.2. General considerations concerning the enthatpies of adsorption: the effect of electron pairing and three-body interactions

In ref. [5], a value of $293 \mathrm{~kJ} \mathrm{~mol}^{-1}$ was taken for the strength of the bond of atomic hydrogen with the Si(111) surface, while for all silicon containing adsorbates a value of $226 \mathrm{~kJ} \mathrm{~mol}^{-1}$ was used for the $\mathrm{Si}-\mathrm{Si}$ bond strength. However, bond strengths may vary significantly dependent on hybridization and substituents. In this section these effects will be evaluated in detail in order to refine the surface bond strengths in ref. [5]. To this purpose both electron pairing and three-body interactions will be considered first.

\subsubsection{Electron pairing energies}

When a silicon atom has only two atoms attached to it, the configuration with the lowest energy will be the one in which the two remaining valence electrons are combined in a lone pair. This 
Table 1

Electron pairing energies of silicon compounds at $298 \mathrm{~K}$

\begin{tabular}{llc}
\hline Compound & Electron pairing energy $\left(\mathrm{kJ} \mathrm{mol}^{-1}\right)$ & Selected numbers $\left(\mathrm{kJ} \mathrm{mol}^{-1}\right)$ \\
\hline $\mathrm{SiH}$ & $-142.7[12]$ & -143 \\
$\mathrm{SiH}_{2}$ & $-68.6[12],-73.6[13,14],-50.2[15],-72.4[16]$ & -72 \\
$\mathrm{H}_{3} \mathrm{SiSiH}$ & $-39.0[15],-43.1[12]$ & -41 \\
$\mathrm{H}_{2} \mathrm{SiSiH}_{2}$ & $-146.4[8],-82.0[12],-104.6,-143.5[17],-159.0[18]$ & -146 \\
$\mathrm{Si}_{3}$ & $-6.3[19]$ & -6 \\
$\mathrm{H}_{3} \mathrm{SiSiSiH}_{3}$ & $-25.1[20]$ & -25 \\
\hline
\end{tabular}

is consistent with the ground electronic state of $\mathrm{SiH}_{2}$, which was found to be the ${ }^{1} \mathrm{~A}_{1}$ state and not the ${ }^{3} \mathrm{~B}_{1}$ state (see ref. [11] and references therein). This implies that if a species like $\mathrm{SiH}_{2}$ is to form a chemical bond with another species, e.g. a crystal surface, the electron pair has to be excited to the diradical state, at the cost of energy.

In table 1 some literature values of the so-called "electron pairing" energy in several silicon compounds are given. The electron pairing energy is the energy released when two valence electrons on a silicon atom form a lone pair. It is clear from this table that because of the high numbers of the electron pairing energies, this effect certainly has to be included in the calculation of the adsorption heats.

In the calculations we used the numbers in the last column of table 1 . The electron pairing energy of $\mathrm{H}_{3} \mathrm{SiSiSiH}_{3}$ of $-25.1 \mathrm{~kJ} \mathrm{~mol}^{-1}$ is required in the calculation of the pairing energy of atoms in the broken bond $\mathrm{Si}(001)$ surface (see below). We want to remark that the value for $\mathrm{H}_{2} \mathrm{SiSiH}_{2}$ given in the table is not of the formation of a lone pair, but of the formation of a $\pi$-bond from the two unpaired valence electrons on the silicon atoms. Furthermore we assume that the $\mathrm{Si}_{3}$ molecule is cyclic in the gas phase, as was shown by Raghavachari [19].

\subsubsection{Three-body interactions}

In table 2, bond dissociation enthalpies at 298 $\mathrm{K}$ of several silicon species are given. From this table it can be seen that the more hydrogen atoms attached to the silicon atoms in a certain compound, the higher the $\mathrm{Si}-\mathrm{Si}$ bond strength becomes.

This implies that even in a very rough estimation it is not enough to use the same value of the surface bond strength for all silicon compounds, as was assumed in ref. [5]. In other words, an interaction term only based on the two atoms directly participating in the surface bond (i.e. pair interaction) is not complete.

Table 2

Bond dissociation enthalpies of several silicon compounds at $298 \mathrm{~K}$

\begin{tabular}{|c|c|c|}
\hline \multirow[t]{2}{*}{ Dissociation reaction } & \multicolumn{2}{|c|}{ Enthalpy change $\left(\mathrm{kJ} \mathrm{mol}^{-1}\right)$} \\
\hline & Literature value & Calculated value \\
\hline $\mathrm{Si}(\mathrm{s}) \rightarrow \mathrm{Si}(\mathrm{g})$ (sublimation of $\mathrm{Si})$ & $452[24]$ & 452 \\
\hline $\mathrm{H}_{3} \mathrm{SiH}_{2} \mathrm{Si}-\mathrm{SiH}_{2} \mathrm{SiH}_{3} \rightarrow \mathrm{H}_{3} \mathrm{SiH}_{2} \mathrm{Si}+\mathrm{SiH}_{2} \mathrm{SiH}_{3}$ & $304[21]$ & 295 \\
\hline $\mathrm{H}_{3} \mathrm{Si}-\mathrm{SiH} \mathrm{SiH}_{3} \rightarrow \mathrm{H}_{3} \mathrm{Si}+\mathrm{SiH}_{2} \mathrm{SiH}_{3}$ & $312[7,21]$ & 310 \\
\hline $\mathrm{H}_{3} \mathrm{Si}-\mathrm{SiH}_{3} \rightarrow \mathrm{H}_{3} \mathrm{Si}+\mathrm{SiH}_{3}$ & $320[7,21]$ & 324 \\
\hline $\mathrm{Si}_{3} \mathrm{Si}-\mathrm{SiH}_{3} \rightarrow \mathrm{Si}_{3} \mathrm{Si}+\mathrm{SiH}_{3}$ & $280[22,23]$ & 281 \\
\hline $\mathrm{H}_{3} \mathrm{Si}-\mathrm{H} \rightarrow \mathrm{H}_{3} \mathrm{Si}+\mathrm{H}$ & $381[7,21,24]$ & 380 \\
\hline $\mathrm{H}_{3} \mathrm{SiH}_{2} \mathrm{Si}-\mathrm{H} \rightarrow \mathrm{H}_{3} \mathrm{SiH}_{2} \mathrm{Si}+\mathrm{H}$ & $364[7,21,24]$ & 366 \\
\hline$\left(\mathrm{H}_{3} \mathrm{Si}\right)_{2} \mathrm{HSi}-\mathrm{H} \rightarrow\left(\mathrm{H}_{3} \mathrm{Si}\right)_{2} \mathrm{HSi}+\mathrm{H}$ & $351[23,24]$ & 352 \\
\hline$\left(\mathrm{H}_{3} \mathrm{Si}\right)_{3} \mathrm{Si}-\mathrm{H} \rightarrow\left(\mathrm{H}_{3} \mathrm{Si}\right)_{3} \mathrm{Si}+\mathrm{H}$ & $339[22-25]$ & 338 \\
\hline
\end{tabular}


Recently, two of the authors developed a theoretical model for the description of the energetic properties of silicon surfaces with and without hydrogen adsorption [26], in which not only pairinteractions but also three-body interactions are considered. This model is an extension and adjustment of the work of Stillinger and Weber, who used pair and triplet potentials to describe interactions in solid and liquid forms of silicon [27]. The potential model of ref. [26] can be used to estimate the strengthening of $\mathrm{Si}-\mathrm{Si}$ bonds by neighbouring hydrogen atoms, in surface-adsorbate bonds as well as gas phase molecules. It turns out that (as long as all the bond angles are approximately equal) this effect can be described adequately with the use of the relations:

$\Delta H_{\mathrm{Si}-\mathrm{Si} \text { bond }}=h_{\mathrm{SiSi}}+i h_{\mathrm{SiSiH}}+j h_{\mathrm{SiSiSi}}$,

$\Delta H_{\mathrm{Si}-\mathrm{H} \text { bond }}=h_{\mathrm{SiH}}+i h_{\mathrm{SiSiH}}+k h_{\mathrm{HSiH}}$,

where $h_{\mathrm{SiSi}}$ and $h_{\mathrm{SiH}}$ are the two-body contributions to the bond strengths, $h_{\mathrm{SiSiH}}$ is a three-body interaction term for two $\mathrm{Si}$ atoms and one $\mathrm{H}$ atom, $h_{\mathrm{SiSiSi}}$ a term for three silicon atoms and $h_{\mathrm{HSiH}}$ for two hydrogen atoms and one silicon atom; $i, j$ and $k$ are the corresponding number of these interactions involved in the bond, e.g. the dissociation reaction $\mathrm{H}_{3} \mathrm{Si}-\mathrm{SiH}_{3} \rightarrow \mathrm{H}_{3} \mathrm{Si}+\mathrm{SiH}_{3}$ can be described with eq. (3) when $i=6$ and $j=0$.

To give an adequate description of the enthalpy changes for the dissociation reactions in table 2 , the following parameters should be taken: $h_{\mathrm{SiSi}}$ and $h_{\mathrm{SiH}}$ equal to 204 and $278 \mathrm{~kJ} \mathrm{~mol}^{-1}$, respectively; $h_{\mathrm{SiSiH}}$ should be taken as $20 \mathrm{~kJ} \mathrm{~mol}^{-1}$, $h_{\mathrm{SiSiSi}}$ as $5.5 \mathrm{~kJ} \mathrm{~mol}^{-1}$ and $h_{\mathrm{HSiH}}$ as $34 \mathrm{~kJ} \mathrm{~mol}^{-1}$. With the aid of these numbers the dissociation enthalpies in the last column of table 2 result. It can be seen that the consistency between literature values and calculated values is quite satisfactory, so that the method can be used with confidence for the calculation of the heats of adsorption.

We want to point out that in the reaction $\mathrm{Si}(\mathrm{s}) \rightarrow \mathrm{Si}(\mathrm{g})$, which is the sublimation of silicon, per silicon atom which is to be removed from the bulk of the lattice, an energy equal to $2 h_{\mathrm{SiSi}}$ plus 8 $h_{\text {Sisisi }}$ has to be raised. Furthermore we want to mention that within the uncertainty range the value of $h_{\mathrm{SiH}}$ is equal to the dissociation enthalpy of the SiH molecule, viz. $285 \mathrm{~kJ} \mathrm{~mol}^{-1}$ [8].

\subsection{General considerations concerning the entropies and heat capacities}

The entropy and heat capacity changes during adsorption are calculated in the same way as was described in ref. [5], with the aid of partition functions. The following structural data will be used: the $\mathrm{Si}-\mathrm{H}$ equilibrium bond length is assumed to be $0.148 \mathrm{~nm}$ for $\mathrm{SiH}_{3, \text { gas }}$ and $\mathrm{SiH}_{2 \text {,ads }}$ and $0.152 \mathrm{~nm}$ for $\mathrm{SiH}_{2, \text { gas }}, \mathrm{SiH}_{\text {gas }}$ and $\mathrm{SiH}_{\mathrm{ads}}$, this in contrast to ref. [5], where for all $\mathrm{Si}-\mathrm{H}$ bond lengths $0.152 \mathrm{~nm}$ was taken. For the $\mathrm{H}-\mathrm{Si}-\mathrm{H}$ bond angle in $\mathrm{SiH}_{2}, 93^{\circ}$ was chosen $[8,12,13,16$, 28-31], for $\mathrm{SiH}_{3}, 111.2^{\circ}[8,16,28,32]$ and for $\mathrm{SiH}_{4}$, $109.5^{\circ}$ (tetrahedral). These angles were also used for compounds and adsorbates with electronically similar central silicon atoms, e.g. the $\mathrm{Si}-\mathrm{Si}-\mathrm{H}$ bond angle in $\mathrm{SiH}$ adsorbed on $\mathrm{Si}(111)$, which may be considered electronicaly similar to gaseous $\mathrm{H}_{3} \mathrm{SiSiH}$, i.e. with a lone pair on the silicon atom, was taken $93^{\circ}$. These somewhat different structural data lead to deviations from the entropy and heat capacity values reported in ref. [5] of a few percent; e.g. the rotational contribution to the adsorption entropy of $\mathrm{SiH}$ at $1400 \mathrm{~K}$ is now calculated to be $-19.7 \mathrm{~J} \mathrm{~K}^{-1} \mathrm{~mol}^{-1}$ instead of $-20.9 \mathrm{~J} \mathrm{~K}^{-1} \mathrm{~mol}^{-1}$

In the estimations of the entropy changes during adsorption on $\mathrm{Si}(111)$ and $\mathrm{Si}(001)-(2 \times 1)$ the following general assumptions are made:

(a) Single-bound species: all translational contributions to the entropy are lost during adsorption. Also the rotational degrees of freedom of the species in the gas phase are lost; however, in some cases (see below) one degree of freedom is gained upon adsorption, viz. rotation around the surfaceadsorbate bond. With regard to the vibrational contributions, we assume one stretching and two bending vibrational modes, in addition to the existing internal vibrations of the adsorbates.

(b) Double-bound species: besides losing all translational contributions to the entropy, these species also lose all rotational degrees of freedom, as no rotation is possible around the surface-adsorbate bonds. For these species we additionally 
assume one bending and two stretch-bending vibrational modes, where it is further assumed that the vibrational force constant is approximately two times that for single-bound species, because of the approximately double surface bond strength in this case.

(c) Quadruple-bound species: here the same assumptions as in (b) are made, with vibrational force constants approximately four times the ones of single-bound species.

The electronic contributions to the entropy change during adsorption are calculated according to the methods discussed in ref. [5].

Below we shall use the following notations: for species with one bond to the surface: $\mu^{1}$, with two bonds: $\mu^{2}$, and with four bonds: $\mu^{4}$. As an exception to this, the notation $\mu^{1}$ will be omitted for species which can only adsorb with one bond to a specific surface.

\subsection{General remarks on the adsorption isotherms}

As in this study also adsorbates occupying more than one adsorption site will be considered, the equations for the calculation of the surface coverage used in ref. [5] have to be reconsidered.

The subject of our interest is the coverage of silicon surfaces with all possible species in all possible configurations. To calculate the different fractions of surface sites covered with species occupying one and species occupying two sites, the following method can be followed (based on the Langmuir model of adsorption):

(a) For species $i$ occupying one site the fractional coverage $\theta_{1, i}$ is given as (see ref. [5]):

$\theta_{1, i}=K_{1, i} p_{i} \theta_{*}$,

with $\theta_{*}$ is the fraction of empty sites, $K_{1, i}$ the adsorption equilibrium constant and $p_{i}$ the partial pressure of the species $i$ in the gas phase.

(b) For species $j$ occupying two surface sites the fraction of sites covered, $\theta_{2, j}$ is given as:

$\theta_{2, j}=2 c K_{2, j} p_{j} \theta_{*}^{2}$,

analogous to eq. (5). This relation follows from the derivation of the configurational part of the partition function of a polymer molecule in solution (the Flory-Huggins polymer solution theory, see e.g. ref. [33]), when the length of the polymer is assumed to be two atoms. In this way account is taken of the requirement that for the adsorption of the double-bound species two neighbouring sites should be unoccupied. The constant $c$ in eq. (6) is the coordination number of the sites on the surface, e.g. for a hexagonal lattice, like $\operatorname{Si}(111), c=6$.

The fraction of empty surface sites, $\theta_{*}$, to be inserted in eqs. (5) and (6), can be calculated with the aid of the equation:

$$
\begin{aligned}
\theta_{*} & =1-\sum_{i=1}^{n} \theta_{1, i}-\sum_{j=1}^{m} \theta_{2, j} \\
& =1-\sum_{i=1}^{n} K_{1, i} p_{i} \theta_{*}-2 c \sum_{j=1}^{m} K_{2, j} p_{j} \theta_{*}^{2},
\end{aligned}
$$

where $n$ and $m$ are the numbers of different species $i$ and $j$, resp. With the equilibrium constants discussed before and the partial pressures from figs. 1 and 2 , eq. (7) can be solved for $\theta_{*}$, and subsequently $\theta_{1, i}$ and $\theta_{2, j}$ can be calculated. In the next sections this will be applied to $\mathrm{Si}(111)$ and dimer reconstructed $\mathrm{Si}(001)$.

\section{Adsorption on $\operatorname{Si(111)}$}

\subsection{Adsorption enthalpies}

When the effects mentioned in the foregoing section are included in the estimation of the adsorption enthalpies of those species in figs. 1 and 2 which in our view are able to form a chemical bond with the $\mathrm{Si}(111)$ surface, the data of table 3 result. We think it useful to discuss the origin of these data in more detail:

(a) For the adsorbates $\mathrm{Si}, \mathrm{SiH}, \mathrm{SiH}_{3}, \mathrm{SiH}_{2} \mathrm{SiH}_{3}$ and $\mu^{1}-\mathrm{Si}_{2}$ the adsorption enthalpy was derived with the aid of eq. (3) (note that the adsorption enthalpy is the negative of the bond strength); for $\mathrm{H}$ it was derived with the aid of eq. (4).

(b) The adsorption enthalpy of the species $\mathrm{SiH}_{2}, \mathrm{H}_{3} \mathrm{SiSiH}$ and $\mu^{1}-\mathrm{H}_{2} \mathrm{SiSiH}_{2}$ was derived with the aid of eq. (3) and the pairing energies in table 1 (the pairing energies make the adsorption enthalpies less negative). 
Table 3

Enthalpy and entropy changes at $298 \mathrm{~K}$ for adsorption on $\mathrm{Si}(111)$

\begin{tabular}{lcl}
\hline Species & $\begin{array}{l}\Delta H_{\mathrm{ad}, 298}^{\circ} \\
\left(\mathrm{kJ} \mathrm{mol}^{-1}\right)\end{array}$ & $\begin{array}{l}\Delta S_{\mathrm{ad}, 298}^{\circ} \\
\left(\mathrm{J} \mathrm{K}^{-1} \mathrm{~mol}^{-1}\right)\end{array}$ \\
\hline $\begin{array}{l}\text { Species } \\
\mathrm{H}\end{array}$ & -338 & -117 \\
$\mathrm{Si}$ & -221 & -118 \\
$\mathrm{SiH}$ & -241 & -127 \\
$\mathrm{SiH}$ & -189 & -129 \\
$\mathrm{SiH}_{3}$ & -281 & -155 \\
$\mathrm{Si}_{2} \mathrm{H}_{5}$ & -266 & -191 \\
$\mathrm{H}_{3} \mathrm{SiSiH}_{\mathrm{SiS}}$ & -205 & -176 \\
$\mu^{1}-\mathrm{H}_{2} \mathrm{SiSiH}$ & -120 & -179 \\
$\mu^{1}-\mathrm{Si}_{2}$ & -226 & -140 \\
$\mu^{1}-\mathrm{Si}_{3}$ & -217 & -218 \\
$\mathrm{Species}_{3}$ with two bonds to the surface & \\
$\mu^{2}-\mathrm{H}_{2} \mathrm{SiSiH}_{2}$ & -315 & -253 \\
$\mu^{2}-\mathrm{Si}_{2}$ & -406 & -202 \\
$\mu^{2}-\mathrm{Si}_{3}$ & -340 & -278 \\
\hline
\end{tabular}

(c) The adsorption enthalpy of $\mu^{1}-\mathrm{Si}_{3}$ was also derived with the aid of eq. (3) and table 1; however, in this case we included a small term to correct for the loss of resonance possibilities during adsorption. This term was estimated to be approximately $7 \%$ [34] of a total resonance energy of $262 \mathrm{~kJ} \mathrm{~mol}^{-1}$ [19].

(d) For the double-bound species the adsorption enthalpy is estimated as follows:

(i) For $\mu^{2}-\mathrm{Si}_{2}$ we have:

$$
\Delta H_{\mathrm{ad}, 298}^{\circ}=-2 h_{\mathrm{SiSi}}-8 h_{\mathrm{SiSiSi}}+h_{\mathrm{def}, \mathrm{Si}_{2}} \text {, }
$$

where $h_{\mathrm{def} \mathrm{Si}_{2}}$ is the enthalpy change caused by the deviation of the surface bond angles from the energetically most favourable tetrahedral value of $109.5^{\circ}$. With the aid of the potential model of ref. [26] this term is calculated to be $46 \mathrm{~kJ} \mathrm{~mol}^{-1}$.

(ii) For $\mu^{2}-\mathrm{H}_{2} \mathrm{SiSiH}_{2}$ we have:

$$
\begin{aligned}
\Delta H_{\mathrm{ad} .298}^{\circ}= & -2 h_{\mathrm{SiSi}}-8 h_{\mathrm{SiSiSi}}-4 h_{\mathrm{SiSiH}}-P_{\mathrm{H}_{2} \mathrm{SiSiH}_{2}} \\
& +h_{\mathrm{def}, \mathrm{H}_{2} \mathrm{SiSiH}_{2}},
\end{aligned}
$$

where $P_{\mathrm{H}_{2} \mathrm{SiSiH}_{2}}$ is the electron pairing energy of table 1; in this case the deformation enthalpy $h_{\text {def, } \mathrm{H}_{2} \mathrm{SiSiH}_{3}}$ is calculated to be $71 \mathrm{~kJ} \mathrm{~mol}^{-1}$ [26].

(iii) For $\mu^{2}-\mathrm{Si}_{3}$ we get:

$$
\Delta H_{\mathrm{ad}, 298}^{\circ}=-h_{\mathrm{SiSi}}-6 h_{\mathrm{SiSiSi}}+\Delta R_{\mathrm{Si}_{3}}+h_{\text {relax }, \mathrm{Si}_{3}},
$$

where $\Delta R_{\mathrm{Si}_{3}}$ is the resonance energy mentioned in (c). This species has the possibility to relax to the energetically favourable tetrahedral angles upon adsorption, which leads to a lowering in enthalpy. This relaxation enthalpy, $h_{\text {relax }, \mathrm{Si}_{i}}$, is estimated to be $-121 \mathrm{~kJ} \mathrm{~mol}^{-1}$ [26]. Note that in this case the pair interaction is taken only once. This is done so because if it is assumed that $\mathrm{Si}_{3}$ has a cyclic form in the gas phase [19], one $\mathrm{Si}-\mathrm{Si}$ bond has to be broken in the molecule in order to form two bonds with the surface. In this procedure the electron pairing energy will not be affected.

\subsection{Adsorption entropies and heat capacities}

In table 3 , the calculated changes in entropy for adsorption on Si(111) at $298 \mathrm{~K}$ are shown. Some of the values differ from the ones reported in ref. [5], because of the somewhat different structural data (see above).

It is calculated that the integrated temperature corrections at, e.g., $1400 \mathrm{~K}$ for the adsorption enthalpy of all species range from -9 to $4 \mathrm{~kJ}$ $\mathrm{mol}^{-1}$, which is absolutely within the range of uncertainties in the estimated heats of adsorption. Therefore we do not specify these values here, although they were taken into account in the calculations.

\subsection{Surface coverage}

With the aid of above adsorption data and eqs. (5) to (7) (taking $c=6$ ), the coverage of the $\mathrm{Si}(111$ ) face was calculated for the gas phase equilibrium compositions of figs. 1 and 2 . The results are shown in figs. 3 and 4.

It can be seen that in both the homogeneous (fig. 3) and the heterogeneous (fig. 4) equilibrium situations, atomic hydrogen is the most important species on the $\mathrm{Si}(111)$ surface, which agrees with the results of ref. [5].

In the homogeneous case, $\mathrm{SiH}_{3}$ is the most important growth species on the surface for temperatures below approximately $1180 \mathrm{~K}$, while at higher temperatures $\mu^{2}-\mathrm{Si}_{2}$ is the most important. In this case the surface coverage of the most important species increases from $3 \times 10^{-3}$ at 800 $\mathrm{K}$ to $5 \times 10^{-2}$ at approximately $1400 \mathrm{~K}$; above 


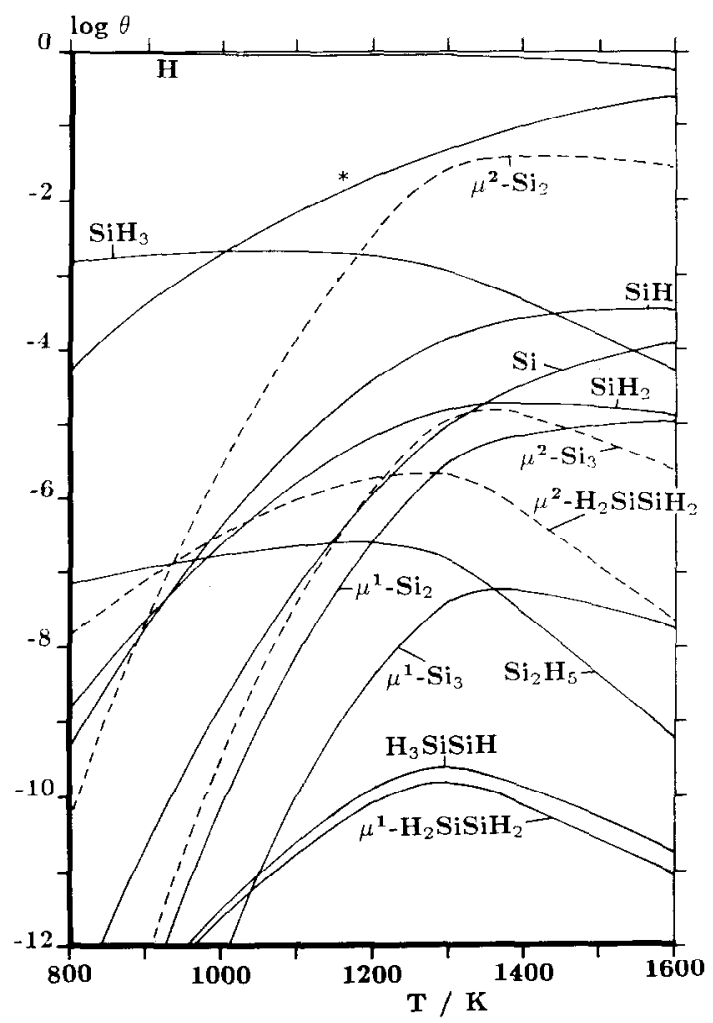

Fig. 3. Equilibrium surface coverage of $\mathrm{Si}(111)$ for the gas phase compositions in fig. 1 (homogeneous equilibrium). * is used to indicate the fraction of empty surface sites. Broken lines indicate double-bound species. The graph is also representative for adsorption on a dimer reconstructed Si(001) surface (see section 5.4).

$1400 \mathrm{~K}$ the surface coverage of $\mu^{2}-\mathrm{Si}_{2}$ decreases to $3 \times 10^{-2}$ at $1600 \mathrm{~K}$. Note that the unsaturated species which are dominant in the gas phase $\left(\mathrm{Si}_{3}\right.$, $\mathrm{SiH}_{2}, \mathrm{H}_{2} \mathrm{SiSiH}_{2}$ ) do not dominate on the surface.

In the heterogeneous case for temperatures below approximately $1450 \mathrm{~K}, \mathrm{SiH}_{3}$ is found to be the most abundant growth species on the surface, while above $1450 \mathrm{~K}, \mathrm{SiH}$ is the most important. The coverages of these species are in the range $4 \times 10^{-8}$ to $1 \times 10^{-6}$, and increase with increasing temperatures.

The above conclusion that $\mathrm{SiH}_{3}$ and $\mu^{2}-\mathrm{Si}_{2}$ are the most important silicon species during epitaxial growth on the $\mathrm{Si}(111)$ surface is clearly in contrast with the assumption of several authors that $\mathrm{SiH}_{2}$ is the main species responsible for the growth of silicon from silane (for a review see, e.g., ref. [35]). The most important reason for this discrepancy is that the gas phase compositions used in our calculations of the surface coverage are equilibrium compositions. We shall illustrate this with an example.

In the equilibrium situations of figs. 1 and 2 at $1200 \mathrm{~K}$, the partial pressure of $\mathrm{SiH}_{3}$ is only slightly different from that of $\mathrm{SiH}_{2}$. In the adsorption layers calculated with these partial pressures, depicted in figs. 3 and 4 , the coverage of $\mathrm{SiH}_{3}$ at $1200 \mathrm{~K}$ is about 300 times that of $\mathrm{SiH}_{2}$. This shift in relative importance as compared to our previous paper [5] is mainly caused by the negative influence of the electron pairing energy on the adsorption properties of $\mathrm{SiH}_{2}$ with respect to those of $\mathrm{SiH}_{3}$.

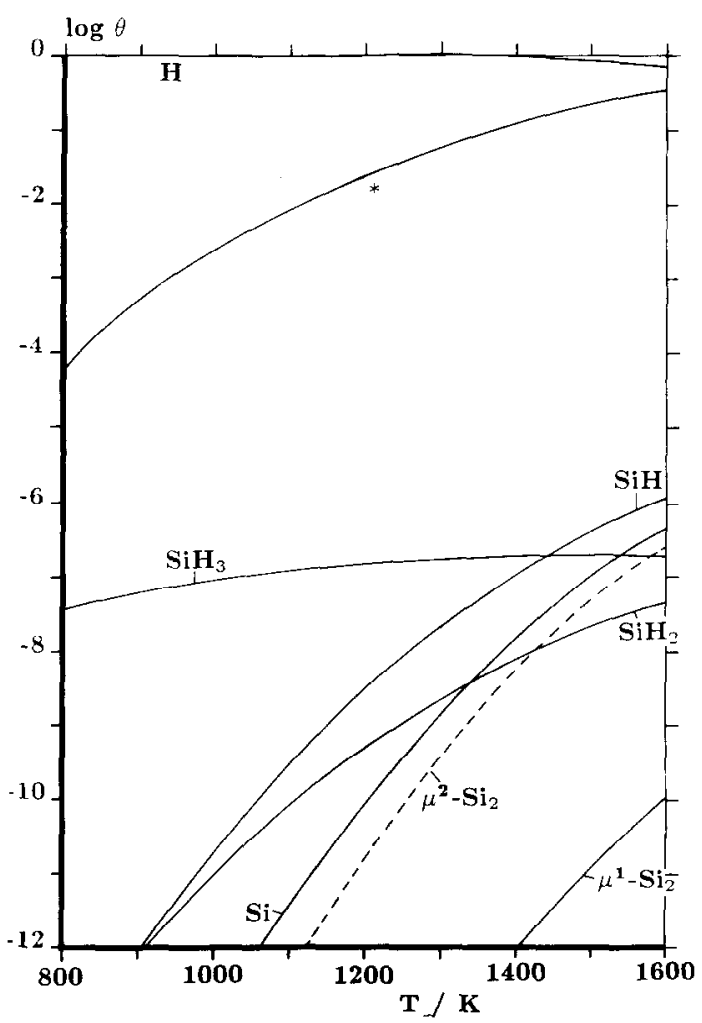

Fig. 4. Equilibrium surface coverage of $\mathrm{Si}(111)$ for the gas phase compositions in fig. 2 (heterogeneous equilibrium). The graph is also representative for adsorption on a dimer reconstructed $\mathrm{Si}(001)$ surface where the dimer bonds remain intact (see section 5). 

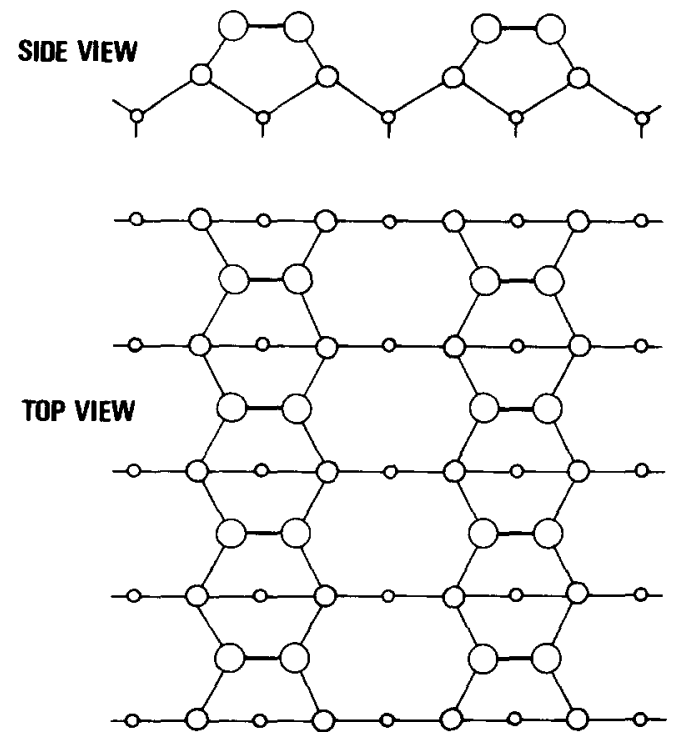

Fig. 5. Schematical drawing of the $\operatorname{Si}(001)-(2 \times 1)$ surface with dimer reconstruction.

However, with the aid of the kinetical data of Coltrin et al. [7] it can be calculated that the rate of formation of $\mathrm{SiH}_{3}$ from $\mathrm{SiH}_{4}$ at, e.g., $1200 \mathrm{~K}$ is approximately $10^{-4}$ times that of $\mathrm{SiH}_{2}$ from $\mathrm{SiH}_{4}$. So in a kinetic picture $\mathrm{SiH}_{2}$ will become much more important in the gas phase than $\mathrm{SiH}_{3}$. This will be reflected on the adsorption layer, which implies that because of the gas phase kinetics $\mathrm{SiH}_{2}$ might still be a more important contributor to the growth of silicon than $\mathrm{SiH}_{3}$. This idea will be pursued in a forthcoming paper.

\section{Adsorption on Si(001)- $(2 \times 1)$}

\subsection{Dimer reconstruction}

In fig. 5 , the atomic structure of the $\mathrm{Si}(001)$ $(2 \times 1)$ surface is shown as it is assumed to be according to recent literature. On this surface, pairs of neighbouring surface atoms form new bonds, which are not present in the bulk of the crystal lattice. As will be discussed below, the newly formed bond consists of a $\sigma$ and a $\pi$ contribution.

A lot of theoretical research has been devoted to the determination of the enthalpy change which occurs upon the formation of a dimer from the surface atoms as present in the broken bond configuration of the (001) surface. From the very extensive literature, a value of $-(200 \pm 40) \mathrm{kJ}$ $\mathrm{mol}^{-1}$ [36-39] can be derived for this enthalpy change.

It is possible to consider the process of the formation of a single dimer from two (001) surface atoms in the broken bond configuration as a consequence of several energy steps. This is outlined in fig. 6. Scanning tunneling microscopy (STM) investigations have shown enhanced electron density between the surface silicon atoms [40], which may indicate that $\pi$-bonding is important in the dimers. This is consistent with a dimer length of $0.228 \mathrm{~nm}$ [38], which is somewhat shorter than the bulk bond length of $0.235 \mathrm{~nm}$.

The enthalpy changes in the different processes depicted in fig. 6 are as follows:

(A) De-pairing of the two $\mathrm{Si}(001)$ surface atoms in the broken bond configuration occurs at the cost of $34 \mathrm{~kJ} \mathrm{~mol}^{-1}$. This number is derived from

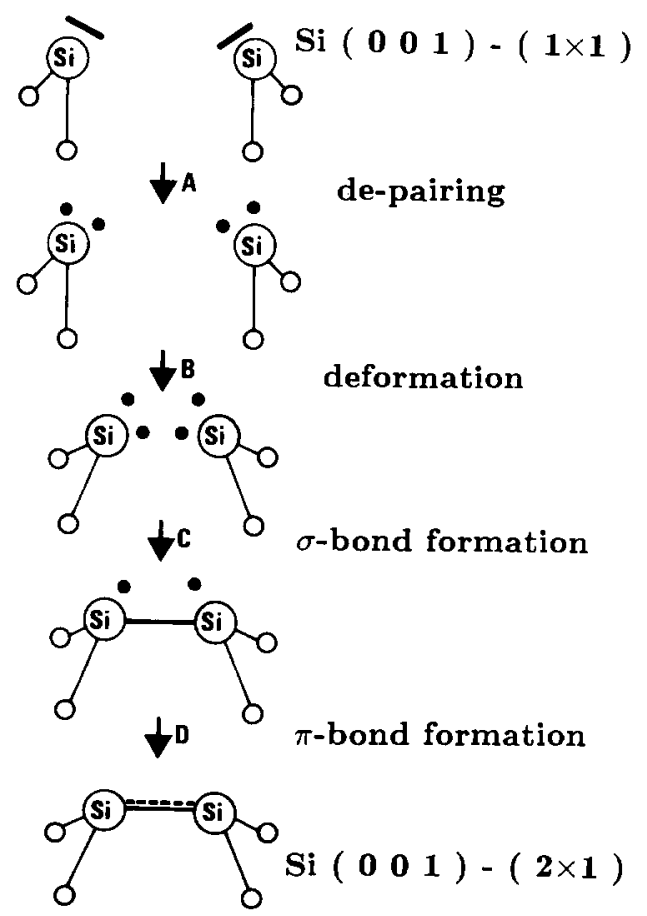

Fig. 6. Schematical drawing to illustrate the different contributions to the dimer binding enthalpy on $\operatorname{Si}(001)-(2 \times 1)$. 
the electron pairing energy of the species $\mathrm{H}_{3} \mathrm{SiSi}-$ $\mathrm{SiH}_{3}$ (see table 1), including corrections [26] for the different bond angle on the surface with respect to the bond angle in the latter compound.

(B) The angle-deformation energy is calculated to be approximately $67 \mathrm{~kJ} \mathrm{~mol}^{-1}$ [26].

(C) The $\sigma$-bond energy is $-226 \mathrm{~kJ} \mathrm{~mol}^{-1}$ (i.e. $\left.-h_{\mathrm{SiSi}}-4 h_{\mathrm{SiSiSi}}\right)$.

(D) The $\pi$-bond energy will be $-59 \mathrm{~kJ} \mathrm{~mol}^{-1}$. This number is derived from the semi-empirical data in ref. [22].

These contributions add to a total reconstruction enthalpy of $-184 \mathrm{~kJ} \mathrm{~mol}^{-1}$, which agrees well with the above mentioned literature values.

\section{SIDE VIEW}

\section{TOP VIEW}
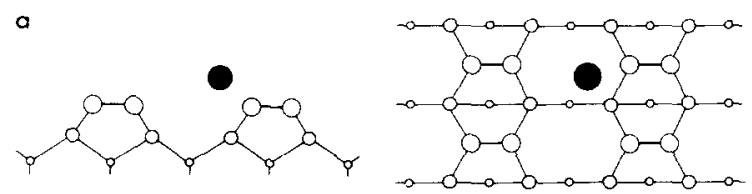

b
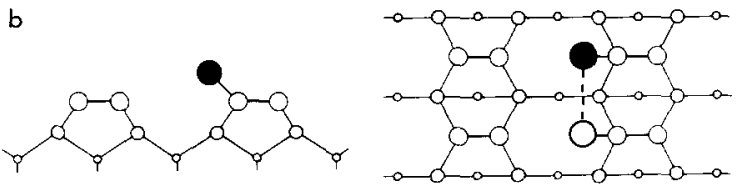

$c$
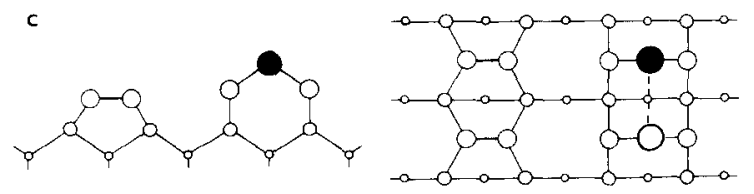

d
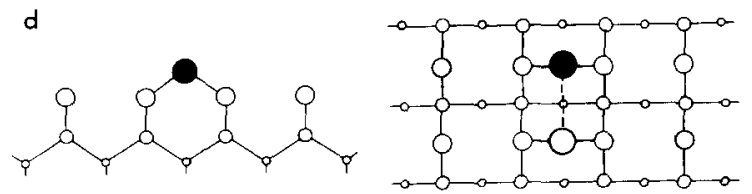

Fig. 7. Possible ways of adsorption on $\mathrm{Si}(001)-(2 \times 1)$. (a) Empty surface plus free gas phase species. (b) Adsorption without the breaking of dimer bonds; in the top view also the configuration of an adsorbate with two bonds to the surface is shown. (c) Adsorption into a dimer bond, with the formation of two bonds to the surface. (d) Adsorption in between two dimer bonds, where both dimer bonds are broken.

\subsection{Adsorption enthalpies}

For each species several ways of adsorption are possible, dependent on the number of dimer bonds broken and the adsorbate position with respect to the dimers. In this study we shall only consider the adsorption processes depicted in fig. 7 , i.e. single, double and fourfold bound adsorbates. In the following sections we will first consider the single-bound adsorbates, followed by the discussion of the adsorbates with two or four bonds to the surface.

\subsubsection{Single-bound species}

These species may adsorb in two different ways: (i) Without the breaking of the $\sigma$ bond. In this process the enthalpy change during adsorption will depend on whether or not already species have adsorbed on one of the atoms which form the dimer bond. If no species has adsorbed yet, the newly adsorbing species have to raise the $\pi$-bond energy, which makes their adsorption enthalpies less negative. On the other hand, if already some species has adsorbed on one of the atoms forming the dimer bond, this $\pi$-bond energy has already been raised. In this latter case it can be calculated with the aid of eqs. (3) and (4) that the adsorption enthalpies are equal to the ones for adsorption on $\mathrm{Si}(111)$

(ii) With the breaking of the complete dimer bond. The enthalpy change in this adsorption process will also depend on the presence and the nature of the species which have already adsorbed on the surface atoms forming the dimer bond. If some species has already adsorbed, say via a $\mathrm{Si}-\mathrm{X}$ bond (X may be $\mathrm{Si}$ or $\mathrm{H}$ ), one $h_{\mathrm{SiSix}}$ term will be lost upon the breaking of the total dimer bond. However, if the new and the old adsorbate are both bound to the same surface atom, an extra threepoint energy term will be gained. Finally, if no species has yet adsorbed on the atoms forming the dimer bond, the newly adsorbing species will have to raise both the $\pi$ and the $\sigma$ contribution to the dimer bond energy.

Suppose we assign numbers to the two surface atoms forming the dimer bond and call the species which has already adsorbed on surface atom I " $X$ " and the one adsorbed on surface atom II 
Table 4

Adsorption enthalpies on $\mathrm{H}$ on atom I of the Si(001)- $(2 \times 1)$ surface at $298 \mathrm{~K}$

\begin{tabular}{llllll}
\hline $\begin{array}{l}\text { Breaking of } \\
\text { dimer? }\end{array}$ & $\mathrm{X}$ & $\mathrm{Y}$ & $\begin{array}{l}\Delta H_{\text {ads }}^{\circ} \\
\left(\mathrm{kJ} \mathrm{mol}^{-1}\right)\end{array}$ & $\begin{array}{l}\text { Enthalpy } \\
\text { correction }\end{array}$ & $\begin{array}{l}\boldsymbol{\theta}_{\mathbf{H}} \text { at } \\
1400 \mathrm{~K}^{\text {b) }}\end{array}$ \\
\hline No & Empty & Empty & -279 & $-\mathrm{D}$ & $4.6 \times 10^{-2}$ \\
No & Empty & $\mathrm{H}$ or Si & -338 & & $8.8 \times 10^{-1}$ \\
Yes & Empty & Empty & -117 & $-\mathrm{B}-\mathrm{C}-\mathrm{D}-\mathrm{A} / 2+h_{\mathrm{SiSiH}}$ & $4.3 \times 10^{-8}$ \\
Yes & $\mathrm{Si}$ & $\mathrm{Empty}$ & -196 & $-\mathrm{B}-\mathrm{C}-\mathrm{A} / 2$ & $3.8 \times 10^{-5}$ \\
Yes & Empty & $\mathrm{Si}$ & -159 & $-\mathrm{B}-\mathrm{C}+h_{\mathrm{SiSiH}}$ & $1.6 \times 10^{-6}$ \\
Yes & $\mathrm{H}$ & $\mathrm{Empty}$ & -190 & $-\mathrm{B}-\mathrm{C}-\mathrm{A} / 2+2 h_{\mathrm{SiSiH}}-h_{\mathrm{HSiH}}$ & $2.3 \times 10^{-5}$ \\
Yes & Empty & $\mathrm{H}$ & -139 & $-\mathrm{B}-\mathrm{C}+2 h_{\mathrm{SiSiH}}$ & $2.8 \times 10^{-7}$ \\
Yes & $\mathrm{Si}$ & $\mathrm{Si}$ & -179 & $-\mathrm{B}-\mathrm{C}$ & $8.9 \times 10^{-6}$ \\
Yes & $\mathrm{H}$ & $\mathrm{H}$ & -153 & $-\mathrm{B}-\mathrm{C}+3 h_{\mathrm{SiSiH}}-h_{\mathrm{HSiH}}$ & $9.5 \times 10^{-7}$ \\
Yes & $\mathrm{H}$ & $\mathrm{Si}$ & -173 & $-\mathrm{B}-\mathrm{C}+2 h_{\mathrm{SiSiH}}-h_{\mathrm{HSiH}}$ & $5.3 \times 10^{-6}$ \\
Yes & $\mathrm{Si}$ & $\mathrm{H}$ & -159 & $-\mathrm{B}-\mathrm{C}+h_{\mathrm{SiSiH}}$ & $1.6 \times 10^{-6}$ \\
\hline
\end{tabular}

a) $\mathrm{A}, \mathrm{B}, \mathrm{C}$ and $\mathrm{D}$ are specified in section 5.1 and fig. $6 ; h_{\mathrm{SiSiH}}$ and $h_{\mathrm{HSiH}}$ are defined in section 3.2 .

b) The hydrogen coverage is calculated for the partial pressure of hydrogen at $1400 \mathrm{~K}$ in fig. 2 (the heterogeneous equilibrium situation).

"Y". X and Y may be either "H", or "Si" (i.e. any species which is bound via a $\mathrm{Si}-\mathrm{Si}$ bond) or "empty" (i.e. no species present). Suppose that the newly adsorbing species adsorbs on surface atom I. Thus, together with the possibility of whether or not the $\sigma$ dimer bond will be broken, for a specific gas phase species a total of eleven different adsorption processes is possible.

As an example of the above we show in table 4 the enthalpy changes in these different adsorption processes for the case of atomic hydrogen. As said above, it is assumed that the newly adsorbing $\mathrm{H}$ atom becomes bound to surface atom I, i.e. the surface atom to which " $\mathrm{X}$ " is already bound.

The adsorption enthalpies in table 4 are derived as follows: the basic adsorption enthalpy of $\mathrm{H}$ on $\mathrm{Si}(001)-(2 \times 1)$ is $-338 \mathrm{~kJ} \mathrm{~mol}^{-1}$, which is the same as the adsorption enthalpy on $\mathrm{Si}(111)$ and is obtained with the aid of eq. (4), taking $n=3$ and $m=0$. This value occurs for adsorption of $\mathrm{H}$ on position I, when already an adsorbate is present on site II of the surface dimer. When no adsorbate is attached to the dimer, the adsorption enthalpy of $\mathrm{H}$ has to be reduced with the $\pi$-bond energy of the dimer, i.e. $\mathrm{D}$ in fig. 6 .

If $i$ is assumed that the adsorption of $\mathrm{H}$ leads to the breaking of the total dimer bond, the above basic adsorption enthalpy of $-338 \mathrm{~kJ} \mathrm{~mol}^{-1}$ has to be reduced with the total reconstruction energy plus $h_{\mathrm{SiSiH}}$; the $h_{\mathrm{SiSiH}}$ term arises because the surface silicon atom after breaking of the dimer bond has only two $\mathrm{Si}$ neighbours, in contrast to the three neighbours in the situation where the dimer bond is intact. Furthermore, the pairing energy of one broken bond surface atom (i.e. $17 \mathrm{~kJ}$ $\mathrm{mol}^{-1}$ ) has to be added. This leads to an adsorption enthalpy of $-117 \mathrm{~kJ} \mathrm{~mol}^{-1}$. Modifications of this value appear as a consequence of the absence or presence of substituents on the original dimer. The corrections on the basic adsorption enthalpy mentioned above are indicated in the table. The enthalpy parameters A, B, C and D are specified at the end of section 5.1 and in fig. 6 .

The last column of table 4 gives the fraction of sites covered with hydrogen, calculated with the use of the data in fig. 2 for a temperature of 1400 $\mathrm{K}$. As can be seen, adsorption of $\mathrm{H}$ is mainly due to saturation of the $\pi$-bond, leaving the $\sigma$-bond intact. Only a minor fraction of the dimer bonds is broken up. It can also be seen that this very small fraction of broken dimer bonds becomes higher, when already adsorbates are present on the dimer bond.

The conclusion from these calculations is that hydrogen adsorption does not lead to the breaking of dimer bonds (at least not at the partial pressures of atomic hydrogen considered in this paper), only the $\pi$-bond will be broken. This is consistent with the results of several recent surface studies [41-45]. Even when the $\operatorname{Si}(001)-(2 \times 1)$ surface is 
subjected to high amounts of atomic hydrogen, not all of the surface dimers are broken [46]. The above means that $\mathrm{H}$ adsorption on a dimer reconstructed (001) surface is analogous to adsorption on a (111) surface.

Similar calculations as in table 4 have been performed for single-bound silicon species. For the simple reason that all these species have lower surface bond strengths than $\mathrm{H}$, the obvious result is that also the single-bound silicon species will adsorb via only the breaking of the $\pi$ part of the dimer bond, but that they are not able to break a significant fraction of the dimer bonds. For that reason we will ignore the insertion of single-bound species into dimer bonds completely.

\subsubsection{Double- and quadruple-bound species}

These species can adsorb either in configuration $b$ or $c$ or $d$ of fig. 7. For the reasons discussed above, the adsorption enthalpy of double-bound adsorbates in situation $b$ in fig. 7 , i.e. in a configuration in between and perpendicular to two dimer bonds, will be the same as on $\mathrm{Si}(111)$, reduced by one or two times the $\pi$-bond energy of the dimer, if already some species have adsorbed on the atoms forming the dimer bonds.

For situations $\mathrm{c}$ and $\mathrm{d}$ of fig. 7, the adsorption enthalpies are listed in table 5. For the species Si, $\mathrm{SiH}, \mathrm{SiH}_{2}$ and $\mathrm{H}_{3} \mathrm{SiSiH}$, we only show the adsorption enthalpies for possibility $c$, i.e. insertion into a dimer bond. The adsorption enthalpy for pro-

Table 5

Adsorption enthalpies of doubly and fourfold bound silicon compounds on $\mathrm{Si}(001)-(2 \times 1)$ at $298 \mathrm{~K}$

\begin{tabular}{llcll}
\hline Species & $\begin{array}{l}\text { Way of } \\
\text { adsorption }\end{array}$ & \multicolumn{2}{c}{$\Delta H_{\text {ads }}^{\circ}\left(\mathrm{kJ} \mathrm{mol}^{-1}\right)$} & $\begin{array}{l}\Delta S_{\text {ads }}^{\circ} \\
\left(\mathrm{J} \mathrm{K}^{-1}\right. \\
\left.\mathrm{mol}^{-1}\right)\end{array}$ \\
\hline$\mu^{2}-\mathrm{Si}$ & $\mathrm{c}$ & -218 & -277 & -141 \\
$\mu^{2}-\mathrm{SiH}$ & $\mathrm{c}$ & -112 & -171 & -172 \\
$\mu^{2}-\mathrm{SiH}_{2}$ & $\mathrm{c}$ & -226 & -285 & -179 \\
$\mu^{2}-\mathrm{H}_{3} \mathrm{SiSiH}$ & $\mathrm{c}$ & -228 & -287 & -241 \\
$\mu^{2}-\mathrm{Si}_{2}$ & $\mathrm{c}$ & -229 & -288 & -202 \\
$\mu^{2}-\mathrm{Si}_{2}$ & $\mathrm{~d}$ & -46 & -114 & -202 \\
$\mu^{4}-\mathrm{Si}_{2}$ & $\mathrm{c}$ & -330 & -448 & -214 \\
$\mu^{4}-\mathrm{Si}_{2}$ & $\mathrm{~d}$ & +38 & -198 & -214 \\
$\mu^{4}-\mathrm{Si}_{3}$ & $\mathrm{c}$ & -164 & -282 & -293 \\
$\mu^{4}-\mathrm{Si}_{3}$ & $\mathrm{~d}$ & +204 & -32 & -293 \\
\hline
\end{tabular}

cess $\mathrm{d}$ would always be $184 \mathrm{~kJ} \mathrm{~mol}^{-1}$ (i.e. the total reconstruction enthalpy) less negative than the values presented in table 5. This way of adsorption is therefore unimportant with respect to the insertion process.

For the species $\mathrm{Si}_{2}$, we show in table 5 the adsorption enthalpies for both ways of adsorption with two or four bonds. Here it can clearly be seen that adsorption process $\mathrm{d}$ in fig. 7 is very improbable: even a positive adsorption enthalpy appears. The same holds for the adsorption of $\mathrm{Si}_{3}$ with four bonds in the d-configuration (see table 5).

Summarizing the results from this section, we can say that on dimer reconstructed $\operatorname{Si}(001)-(2 \times 1)$ two ways of adsorption are likely:

(I) adsorption of single or double-bound species according to $b$ in fig. 7. The corresponding adsorption enthalpies will be similar to those on $\mathrm{Si}(111)$, or, in the case that no substituents are present on the dimers, the values for $\mathrm{Si}(111)$ minus one or two times the $\pi$-bond energy, dependent on the number of adsorbate-surface bonds to be formed.

(II) adsorption according to configuration $\mathrm{c}$ in fig. 7 , i.e. the insertion of species into dimer bonds. This may occur with the formation of two or four adsorbate-surface bonds, dependent on the nature of the species. The corresponding adsorption enthalpies are given in table 5 .

\subsection{Adsorption entropies}

The adsorption entropies for single- and double-bound species, which do not break the dimer bond upon adsorption, are equal to those on $\mathrm{Si}(111)$ (see table 3). The adsorption entropies for species which insert into the dimer bonds are shown in the last column of table 5.

\subsection{Surface coverage}

When it is assumed that no dimer bonds are broken, it can be calculated that in the homogeneous as well as in the heterogeneous equilibrium case the $(001)-(2 \times 1)$ surface will contain atomic hydrogen in fractions ranging from 0.7 at $800 \mathrm{~K}$ to a fraction below 0.05 at $1600 \mathrm{~K}$. However, these coverages are calculated with the assumption that 

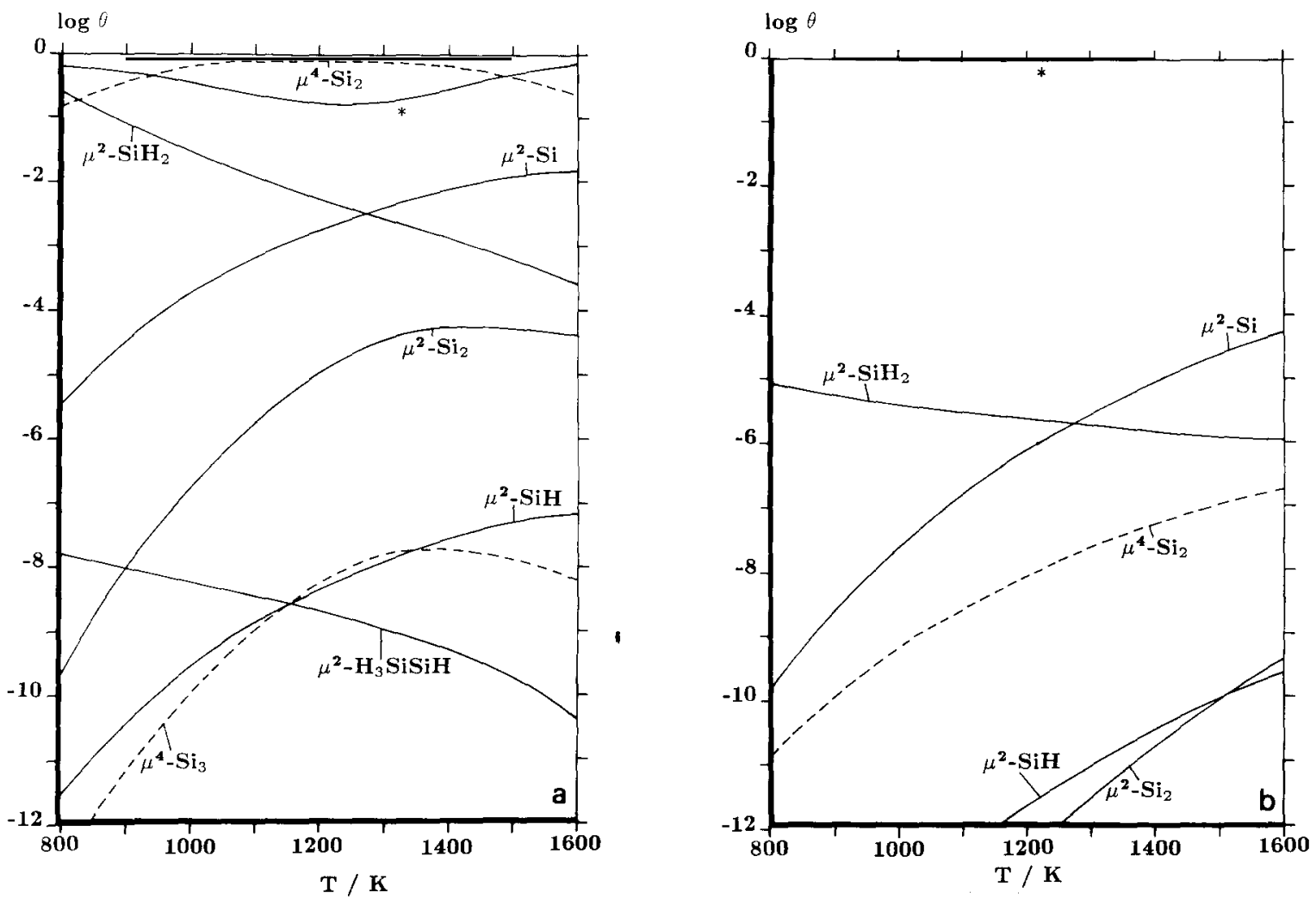

Fig. 8. Equilibrium surface coverage of the Si(001)- $(2 \times 1)$ surface as a function of temperature. The fraction of species inserted into dimer bonds is shown for: (a) the homogeneous equilibrium gas phase composition of fig. 1; (b) the heterogeneous equilibrium gas phase composition of fig. 2 . In this case * is the fraction of unbroken dimer bonds.

the original surface is empty, i.e. all electrons on the surface atoms are shared in $\pi$ and $\sigma$ bonds. Because of the high $\mathrm{H}$ coverage, a newly adsorbing species will not have to raise the dimer $\pi$-bond energy. As was discussed above, this means that the actual adsorption enthalpies of all adsorbates on dimer reconstructed $\mathrm{Si}(001)$ will be very close to (but less negative than) the adsorption enthalpies on Si(111). Therefore the coverage will also be only slightly different from (somewhat lower than) that on the $\mathrm{Si}(111)$ surface represented in figs. 3 and 4. For this reason we do not think it very useful to represent these coverages in a separate figure. It must be noted though that in the $(001)$ case the coverage of the $\mu^{2}$ species is due to adsorption on two neighbouring dimers (leaving the $\sigma$-bonds of the dimers intact). Since on (001)$(2 \times 1)$, the coordination number $c$, to be used in eq. (6), is 2, compared to 6 on (111), the coverage of $\mu^{2}$ species in the (001) case is an extra factor 3 lower than on (111).

Next we shall investigate the insertion of adsorbates into the dimer bonds. As mentioned above, the surface dimers on $\operatorname{Si}(001)-(2 \times 1)$ will most probably have a high amount of hydrogen attached to them. In that case it is best to use the enthalpy data without a $\pi$-bond contribution. The surface coverages calculated with these data are shown in figs. $8 \mathrm{a}$ and $8 \mathrm{~b}$ for the cases of homogeneous and heterogeneous equilibrium, respectively.

It can be seen in fig. $8 \mathrm{a}$ that in the homogeneous equilibrium assumption a large fraction of the dimer bonds is broken as a result of the insertion of $\mu^{4}-\mathrm{Si}_{2}$ species. Furthermore, at lower temperatures, a substantial fraction of the dimer 


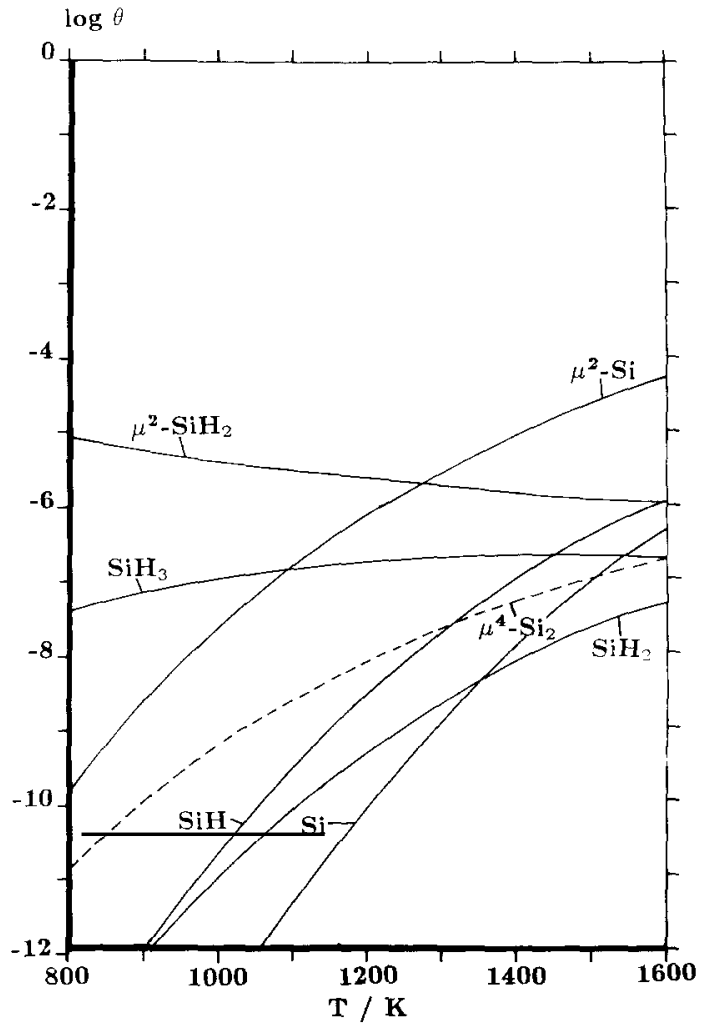

Fig. 9. Total coverage of dimer reconstructed $\mathrm{Si}(001)-(2 \times 1)$ in the heterogeneous equilibrium assumption. This figure is a superposition of figs. 4 and $8 \mathrm{~b}$. Only the species which are relevant in the discussion of growth on this surface are shown.

bonds is broken because of the insertion of $\mathrm{SiH}_{2}$ species, while at temperatures close to $1600 \mathrm{~K}$, a few percent of the dimer bonds are broken by the insertion of atomic Si.

On the other hand, in the heterogeneous equilibrium of fig. $8 \mathrm{~b}$ almost no dimer bonds are broken, while the fraction of inserted species is always lower than $3 \times 10^{-4}$. This proves that during CVD under equilibrium conditions the $(001)$ surface is a stable, dimer reconstructed surface.

Combination of the results of figs. 3 and 4 with those in figs. $8 \mathrm{a}$ and $8 \mathrm{~b}$, respectively, gives a picture of the total coverage of the dimer reconstructed $\mathrm{Si}(001)-(2 \times 1)$ surface. For the heterogeneous case the result is simply a superposition of figs. 4 and 8 b. This is shown in fig. 9 .

Fig. 9 can be interpreted in terms of crystal growth in the following way:

(a) $\mu^{4}-\mathrm{Si}_{2}$ can be considered as small twodimensional nuclei on the surface. It can be seen in fig. 9 that the fractional coverage of this species in the heterogeneous case is relatively low at all temperatures. This means that nucleation on the surface is almost neglegible during growth at low supersaturations, which indicates the F-character of the dimer reconstructed $\mathrm{Si}(001)-(2 \times 1)$ surface (see also ref. [49]).

(b) Because of the before-mentioned F-character, the (001) surface will only grow by the presence of atomic steps. It can be seen in fig. 9 that the species which "feed" these steps during growth might be $\mathrm{SiH}_{3}$ at low temperatures, and $\mathrm{SiH}$ and $\mathrm{Si}$ at higher temperatures, because these species are the most abundant ones with only one bond to the surface and will therefore require the lowest activation energy for surface diffusion to the step edges. However, as was already discussed at the end of section 4.3, one has to be careful with conclusions on the role of $\mathrm{SiH}_{3}$ on the surface, because the gas phase kinetics are in favour of $\mathrm{SiH}_{2}$.

For the homogeneous case, i.e. at high supersaturation, the situation is very different, however. Because a large fraction of the dimer bonds is broken by the adsorption of $\mu^{4}-\mathrm{Si}_{2}$ species (see fig. $8 \mathrm{a})$, the surface has been changed to such an extent that it cannot be considered as a flat $\mathrm{Si}(001)-(2 \times 1)$ surface anymore. That is, adsorbed $\mu^{4}-\mathrm{Si}_{2}$ species can be considered as two surface atoms forming a dimer bond perpendicular to the dimer bonds on the original surface. This is outlined in fig. 10, which shows a top view of the surface with several adsorbed $\mu^{4}$ species close to one another.

If one considers the adsorption on the sites indicated by $D_{2}$ and $D_{4}$ in fig. 10 , it can be seen that on site $D_{2}$ a $\mu^{2}$ species can adsorb in a similar configuration as depicted in fig. $7 \mathrm{~d}$, however, without the necessity to break two dimer bonds. The latter implies that adsorption in this position has become very favourable. Similar reasoning applies to the adsorption of $\mu^{4}$ species in sites $D_{4}$. It follows that on the dimer reconstructed (001) surface adsorbed $\mu^{4}-\mathrm{Si}_{2}$ species actually are small two-dimensional growth clusters and that as a 


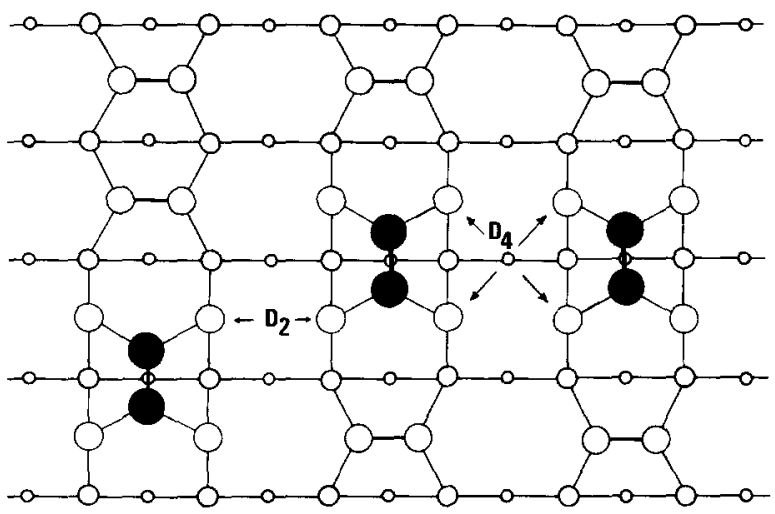

Fig. 10. Schematical drawing of the dimer reconstructed Si $(001)-(2 \times 1)$ surface with several adsorbed $\mu^{4}$ species. $D_{2}$ and $\mathrm{D}_{4}$ indicate the especially favourable adsorption positions for $\mu^{2}$ and $\mu^{4}$ species, respectively, mentioned in the text.

result of the adsorption of these $\mu^{4}-\mathrm{Si}_{2}$ species the surface has become kinetically rough.

Because, as is shown above, the coverage of sites $D_{2}$ and $D_{4}$ depends on the number of broken dimer bonds, the total coverage of the (001) surface cannot be considered as a simple superposition of figs. 3 and 8 a. We think that it is hardly possible to calculate the total surface coverage for this situation with only the methods described in this paper (i.e. with simple Langmuir isotherms). More promising methods to solve problems of this kind probably are molecular dynamics investigations $[48,49]$ or Monte Carlo simulations [26,50].

In our view the actual growth on a (001) surface for normal supersaturation mainly will be governed by the adsorption and diffusion of single bound growth species. This idea is based on the experimentally observed step features (see, e.g., ref. [47]). Extra steps are generated however by the adsorption of $\mu^{4}$ or $\mu^{2}$ silicon species which act as nucleation centra on the surface between the steps.

\section{Final remarks}

The derived value of $-338 \mathrm{~kJ} \mathrm{~mol}^{-1}$ for the enthalpy of adsorption of $\mathrm{H}$ on the $\mathrm{Si}(111)$ (table $3)$ and the hydrogen-covered $\mathrm{Si}(001)-(2 \times 1)$ (table 4) surfaces and the value of $-279 \mathrm{~kJ} \mathrm{~mol}^{-1}$ for the enthalpy of adsorption of $\mathrm{H}$ on an empty
Si $(001)-(2 \times 1)$ surface (table 4$)$ can be compared with several recently published adsorption heats of hydrogen: values ranging from -300 to $-340 \mathrm{~kJ}$ $\mathrm{mol}^{-1}$ were found for adsorption on Si(111) [51], while for adsorption on poly-crystalline $\mathrm{Si}$ values of $-318 \mathrm{~kJ} \mathrm{~mol}^{-1}$ [52], -308 and $-354 \mathrm{~kJ} \mathrm{~mol}^{-1}$ [41] were reported. For adsorption on amorphous Si values ranging from -270 to $-360 \mathrm{~kJ} \mathrm{~mol}^{-1}$ [22] and $-328 \mathrm{~kJ} \mathrm{~mol}^{-1}$ [53] were reported. Finally, two of the authors of the present paper recently have derived an adsorption heat of -316 $\pm 5 \mathrm{~kJ} \mathrm{~mol}^{-1}$ for the adsorption of $\mathrm{H}$ on partially chlorine-covered silicon surfaces with crystallographic orientations in the $\langle 110\rangle$ zones [54].

Note that all the above values are within the range -270 to $-360 \mathrm{~kJ} \mathrm{~mol}^{-1}$, which in fact is a relatively small range considering that these values are measured or calculated for different crystallographic orientations and for different surface coverages.

\section{Summary}

In this study, thermodynamical data were derived for the adsorption of those gas phase species which might be important in the chemical vapour deposition of silicon from silane. In the estimations of the enthalpies electron pairing effects and two- and three-body interactions were included. The adsorption processes on two different surfaces were discussed, viz. Si(111) and dimer-reconstructed $\mathrm{Si}(001)-(2 \times 1)$. Of the species in the gas phase which may adsorb on these surfaces, some may adsorb in different configurations, viz. with one, two or even four bonds to the surface. It was assumed that adsorption on $\mathrm{Si}(111)$ occurs on the dangling bonds which are present on the broken bond surface, and it was demonstrated that on the Si(001)- $(2 \times 1)$ surface adsorption may occur on the atoms involved in the dimers, without the breaking of the dimer bonds, but that if species have the capacity to form two or four bonds with the surface, the adsorption of these species into the dimers is more likely.

The coverage of the $\mathrm{Si}(111)$ and the dimer reconstructed $\mathrm{Si}(001)-(2 \times 1)$ surfaces as a function of temperature was calculated for two differ- 
ent gas phase compositions, viz. for zero and for high supersaturation. It was shown that at zero supersaturation, the equilibrium silicon coverage of the $\mathrm{Si}(111)$ and $\mathrm{Si}(001)-(2 \times 1)$ surfaces is low, which indicates that on these two faces a barrier to the formation of two-dimensional growth clusters is present.

\section{Acknowledgements}

The authors want to thank Dr. H. de Moor, who initiated the theoretical study of adsorption processes on $\mathrm{Si}(001)$, and Dr. M. de Croon for his critical remarks on the adsorption data. One of the authors (J.G.E. Gardeniers) acknowledges the support of the Dutch Foundation for Chemical Research (NWO/SON).

\section{References}

[1] A.A. Chernov and N.S. Papkov, Soviet Phys.-Dokl. 21 (1976) 300.

[2] A.A. Chernov and N.S. Papkov, Kristallografiya 22 (1977) 35.

[3] A.A. Chernov, J. Crystal Growth 42 (1977) 55.

[4] A.A. Chernov and M.P. Rusaikin, J. Crystal Growth 45 (1978) 73 .

[5] L.J. Gilling, H.H.C. de Moor, W.P.J.H. Jacobs and A.A. Saaman, J. Crystal Growth 78 (1986) 303.

[6] P. Ho, M.E. Coltrin, J.S. Binkley and C.F. Melius, J. Phys. Chem. 89 (1985) 4647.

[7] M.E. Coltrin, R.J. Kee and J.A. Miller, J. Electrochem. Soc. 133 (1986) 1206.

[8] P. Ho, M.E. Coltrin, J.S. Binkley and C.F. Melius, J. Phys. Chem. 90 (1986) 3399.

[9] M.E. Coltrin, R.J. Kee and J.A. Miller, J. Electrochem. Soc. 131 (1984) 425.

[10] K. Christmann, Surface Sci. Rept. 9 (1988) 1.

[11] L. Fredin, R.H. Hauge, Z.H. Kafafi and J.L. Margrave, J. Chem. Phys. 82 (1985) 3542.

[12] B.T. Luke, J.A. Pople, M.B. Krogh-Jespersen, Y. Apeloig, J. Chandrasekhar and P.R. Schleyer, J. Am. Chem. Soc. 108 (1986) 260.

[13] K. Krogh-Jespersen, J. Am. Chem. Soc. 107 (1985) 537.

[14] J.E. Rice and N.C. Handy, Chem. Phys. Letters 107 (1984) 365.

[15] T.N. Bell, A.F. Kieran, K.A. Perkins and P.G. Perkins, J. Phys. Chem. 88 (1984) 1334.

[16] W.D. Allen and H.F. Schaefer, Chem. Phys. 108 (1986) 243.
[17] M.W. Schmidt, P.N. Truong and M.S. Gordon, J. Am. Chem. Soc. 109 (1987) 5217.

[18] G. Trinquier and J.P. Malrieu, J. Am. Chem. Soc. 109 (1987) 5303.

[19] K. Raghavachari, J. Chem. Phys. 83 (1985) 3520.

[20] M.S. Gordon and D. Bartols, J. Am. Chem. Soc. 109 (1987) 5948.

[21] R. Walsh, Acc. Chem. Res. 14 (1981) 246.

[22] D.C. Allan, J.D. Joannopoulos and W.B. Pollard, Phys. Rev. B25 (1982) 1065.

[23] M.B. Coolidge and W.T. Borden, J. Am. Chem. Soc. 110 (1988) 2298.

[24] JANAF Thermochemical Tables, J. Phys. Chem. Ref. Data 11 (1982) supplement, p. 695.

[25] F. Illas, J. Rubio and J.M. Ricart, Phys. Rev. B31 (1985) 8068.

[26] J.P. van der Eerden, Liu Guang-Zhao, F. de Jong and M.J. Anders, J. Crystal Growth 99 (1990) 106.

[27] F.H. Stillinger and T.A. Weber, Phys. Rev. B31 (1985) 5262.

[28] D. Power, P. Brint and T. Spalding, J. Mol. Struct. 17 (1984) 81

[29] M.J.S. Dewar, E.F. Healy, J.J.P. Stewart, J. Friedheim and G. Gilady, Organometallics 5 (1985) 375.

[30] M.J.S. Dewar and C. Jie, Organometallics 6 (1987) 1486.

[31] B.T. Luke, J.A. Pople, M.B. Krogh-Jespersen, Y. Apeloig, M. Karni, J. Chandrasekhar and P.R. Schleyer, J. Am. Chem. Soc. 108 (1986) 270.

[32] M.R. Nimlos and G.B. Ellison, J. Am. Chem. Soc. 108 (1986) 6522 .

[33] T.L. Hill, An Introduction to Statistical Thermodynamics (Addison-Wesley, Reading, MA, 1960) p. 124.

[34] M.H.J.M. de Croon, unpublished

[35] J.M. Jasinski, B.S. Meyerson and B.A. Scott, Ann. Rev. Phys. Chem. 38 (1987) 109.

[36] M.T. Yin and M.L. Cohen, Phys. Rev. B24 (1981) 2303.

[37] K.C. Pandey, in: Proc. 17th Intern. Conf. on Physics of Semiconductors, Eds. D.J. Chadi and W.A. Harrison (Springer, Berlin, 1985) p. 55.

[38] J. Tersoff, Phys. Rev. Letters 56 (1986) 632.

[39] K.E. Khor and S. Das Sarma, Phys. Rev. B39 (1989) 1188.

[40] R.J. Hamers, R.M. Tromp and J.E. Demuth, Phys. Rev. B34 (1986) 5343.

[41] P. Gupta, V.L. Colvin and S.M. George, Phys. Rev. B37 (1988) 8234.

[42] T. Sakurai and H.D. Hagstrum, Phys. Rev. B14 (1976) 1593.

[43] R.M. Tromp, R.G. Smeenk and F.W. Saris, Surface Sci 104 (1981) 13.

[44] W.S. Verwoerd, Surface Sci. 108 (1981) 153.

[45] Y.J. Chabal and K. Raghavachari, Phys. Rev. Letters 53 (1984) 282.

[46] Y.J. Chabal and K. Raghavachari, Phys. Rev. Letters 54 (1985) 1055.

[47] L.J. Gilling and W.J.P. van Enckevort, Surface Sci. 161 (1985) 567. 
[48] D.W. Brenner and B.J. Garrison, Surface Sci. 198 (1988) 151.

[49] D. Srivastava, B.J. Garrison and D.W. Brenner, Phys. Rev. Letters 63 (1989) 302.

[50] S.A. Barnett and A. Rockett, Surface Sci. 198 (1988) 133.

[51] G.S. Schulze and M. Henzler, Surface Sci. 124 (1983) 336.
[52] K.W. Frese, Jr., Surface Sci. 182 (1987) 85.

[53] K. Zellama, P. Germain, S. Squeland, B. Bourdon, J. Fontenille and R. Danielou, Phys. Rev. B23 (1981) 6648.

[54] J.G.E. Gardeniers, M.M.W. Mooren, M.H.J.M. de Croon and L.J. Gilling, J. Crystal Growth 102 (1990) 233. 